\title{
Redes de saberes: pensamento interdisciplinar
}

\author{
Cristina Novikoff \\ Marcus Alexandre de Pádua Cavalcanti
}

\section{Redes de Saberes: Pensamento Interdisciplinar}

Resumo: $\mathrm{O}$ artigo discute a importância da articulação entre diferentes conhecimentos sob a perspectiva de redes e propõem que saberes práticos e teóricos pode habitar um mesmo espaço, se influenciando mutuamente. Portanto, objetiva demonstrar que o fenômeno que a princípio parece objeto de estudo de uma única disciplina, também pode ser estudado por outras, evidenciando que modificações e influências mútuas ocorrem quando diferentes modalidades de conhecimentos convivem em um mesmo trabalho. Para tal desafio são apresentados argumentos propositivos de conexão entre as disciplinas, como instrumentos praxiológico, para promover a superação do saber fragmentado. Aduz-se a educação interdisciplinar como práxis contemporânea do saber. A crítica à fragmentação dos saberes é sustentada nas discussões epistemológicas acerca da complexidade e dos paradigmas do conhecimento, em especial, na derivação do pensamento a partir da filosofia de Deleuze e Guattari, que se configura como uma prática rizomática, em contraponto ao modelo epistemológico arbóreo cartesiano.

Palavras-chave: Rede. Interdisciplinaridade. Conhecimento.

\section{Knowledge Networks: Interdisciplinary Thinking}

Abstract: The article discusses the importance of coordination between different knowledge from the perspective of networks and proposes practical and theoretical knowledge can inhabit the same space, influencing each other. Therefore, objectively demonstrate that the phenomenon that at first seems studied by a single discipline, can also be studied by others showing that changes and mutual influences occur when different forms of knowledge coexist in the same work. For this challenge is presented propositional arguments connection between disciplines, as praxeological instruments to promote the overcoming of fragmented knowledge. Assumes that the interdisciplinary education is the contemporary praxis of knowledge. The criticism of the fragmentation of knowledge is sustained in epistemological discussions about the complexity and paradigms of knowledge, especially in the derivation of thought from the philosophy of Deleuze and Guattari, which is configured as a rhizomatic practice as opposed to the epistemological model tree Cartesian.

Keywords: Network. Interdisciplinarity. Knowledge. 


\section{Introdução}

O paradigma mecanicista, que surgiu na modernidade clássica com o filósofo René Descartes tem seu início nos meados do século XVII, e promoveu o que se entende hoje por compartimentarização do conhecimento, em que o conteúdo é tratado em sua forma fragmentada, dividida e separada da complexidade da realidade. Isso deu origem à especialização do conhecimento e, consequentemente, ao formato disciplinar da educação tradicional. No interior desse modelo de educação, é marcante a presença do saber compartimentado. Não há conexões entre as disciplinas, em consequência disso, elas são apresentadas aos estudantes como conhecimentos separados uns dos outros, criando barreiras para que os discentes possam experimentar uma concepção do conhecimento como um todo (GALLO, 2008).

$\mathrm{Na}$ contemporaneidade surgem teorias educacionais que privilegiam uma abordagem direcionada especificamente para a interconexão de diferentes tipos de saberes, estes oriundos de diferentes esferas do conhecimento, possibilitando-se assim, um processo educacional dirigido para a chamada interdisciplinaridade. Este frequente diálogo entre as disciplinas pode ser visto sob uma variedade de níveis que se diferenciam no modo e na intensidade com que irão construir suas linhas de relações e interações. (KRESS, 2003)

Segundo Gallo (2008), a educação interdisciplinar parece ser a medida corrente para superar essa fragmentação do saber. Como resposta a tal problema, tem-se aludido sobre a proposta de uma pedagogia rizomática, com base nos comentários em volta do pensamento de do filosofo francês Gilles Deleuze, que não dedicou obras especificamente ligadas a questões educacionais, mas que apresentou elementos para isso, principalmente ao criticar o modelo de conhecimento fundamentado na estrutura arbórea. Como contraponto e alternativa à metáfora da árvore, Deleuze e Guattari (1995) lançam, no campo de produção do conhecimento, a noção de rizoma ${ }^{1}$. O conceito de rizoma surge em oposição à forma segmentada de se perceber a realidade, bem como ao modo positivista de se construir conhecimento. $\mathrm{O}$ que se pretende nesse artigo é conectar e problematizar a proposta do modelo rizomático como forma de produção de conhecimento.

\section{A Modernidade e o Pensamento Fragmentado}

O fenômeno da hiperespecialização faz com que um verdadeiro mosaico de objetos, cerrados, fechados, disciplinares não possam se comunicar uns com os outros [...] nessa especialização produz-se outro fenômeno, que é a fragmentação [...], que leva à perda de visão da realidade como um todo complexo (MORIN, 2000, p. 23).

A subordinação do múltiplo pelo uno é uma das principais características do pensamento ocidental ao longo da história. Na maior parte das vezes, o múltiplo só foi concebido para estabelecer o uno por oposição dialética. A metafísica é resultado do

\footnotetext{
${ }^{1}$ Rizoma é um conceito utilizado por Deleuze e Guattari (1995), nas ciências sociais, a partir de uma apropriação de um conceito da Botânica, área da Biologia que estuda as plantas. Nessa área, rizoma refere-se a um tipo de caule que algumas plantas verdes possuem que cresce horizontalmente. Esses autores apropriaram-se desse conceito para explicitar fenômenos sociais nos quais não se determina um começo ou fim; os fenômenos estão sempre no meio, imbuídos de outros fenômenos, em intermezzo, sem uma causa definida ou consequência preestabelecida.
} 
pensamento binário que privilegia a transcendência em detrimento da imanência. $\mathrm{O}$ pensamento por oposição, separação, conceituação e classificação tornou-se predominante desde o período da Grécia antiga. Platão foi o precursor do paradigma arborescente, metáfora tradicional da estrutura do conhecimento utilizado pelas diversas áreas de saber (STENGERS, 2001).

Segundo Stengers (idem), é na idade moderna, com a invenção da ciência, que a fragmentação dos saberes se expande. É necessário que tudo o que queira ganhar estatuto de verdade, possa ser quantificado e classificado no interior de um determinado campo de saber. As polarizações que resultam desta dependência entre - sujeito-objeto, homem natureza - se dão por uma imposição do racional ao corpóreo, bem como pela cientificização e objetivação da compreensão do mundo. Esta característica do ocidente, onde tudo é separado e compartimentarizado se estendeu a todas as instâncias das vidas, até a organização do pensamento. De acordo com Deleuze; Guattari (1995), a lógica essencial da árvore foi constantemente remeter-se a um elemento conceitual, classificatório e reducionista. A própria concepção de ivíduo é uma idéia segmentada, assim como a dicotomia entre sujeito e objeto.

Somos segmentarizados por todos os lados e em todas as direções. O homem é um animal segmentário. A segmentaridade pertence a todos os estratos que nos compõe. Habitar, circular, trabalhar, brincar: o vivido é segmentarizado espacialmente e socialmente. A casa é segmentarizada conforme a destinação de seus cômodos; as ruas, conforme a ordem da cidade; a fábrica, conforme a natureza dos trabalhos e das operações (Guattari, 1995).

De acordo com Rouanet (1993), a crença de que esse modelo epistemológico produziria maior objetividade às análises, fez com que a ciência se tornasse imensamente valorizada na modernidade, por se crer em sua neutralidade. Ademais, o programa sócio-cultural da modernidade se compunha de duas dimensões intimamente vinculadas. A primeira delas, tratava de conhecer racional e cientificamente a natureza para melhor sujeita-la, controla-la e explora-la do ponto de vista da obtenção de recursos e bens materiais como forma de otimizar as condições de reprodução social. Mas havia também uma segunda linha que operava simultaneamente com esta, que pensava que, a partir de um conhecimento também racional da sociedade, poder-se-ia organiza-la melhor, entendendo-se essa organização racional como um modo de articulação social que garantisse autonomia e liberdade aos seres sociais singulares. Tratava-se então de racionalizar o intercambio entre a sociedade e a natureza Para o pensamento moderno, essas duas vias de força sinalizavam que era possível criar uma sociedade emancipada. $\mathrm{O}$ controle sobre a natureza e sobre a sociedade foi um projeto da modernidade que até hoje tem reflexos em nossos corpos e nossas vidas. Da modernidade a humanidade herdou a crença de que o ser humano é independente das coisas que produz e que os juízos produzidos pela ciência são realmente verdadeiros, pois sua objetividade faz com que um acontecimento venha à tona. A maior parte dos métodos de pesquisas, elaborados na modernidade, possuíam um caráter quantitativo que buscava justamente à classificação e a hierarquização, a conceituação - a intenção era a busca da identidade, enfatizando com isso a crença de que o pesquisador pode ser neutro em relação á pesquisa que realiza. 
Segundo Gallo (2008), o conhecimento é colocado, classicamente, sob a metáfora da árvore. $\mathrm{O}$ modelo arborescente é a estrutura de onde deve partir todo o conhecimento, inclusive no sentido precisamente cartesiano. Descartes utiliza a imagem da árvore para descrever o todo ou a totalidade do conhecimento. São identificadas as raízes, ou seja, a origem do tronco, e, portanto, do próprio conhecimento. Por se erguer sobre premissas irrefutáveis, o tronco precisa ser firme, pois se ramificam todas as áreas do conhecimento, representadas pelos os galhos. E, assim, emerge a problemática dessa metáfora, demonstrando como o processo arborescente do conhecimento conduz da raiz ao galho, às especializações do conhecimento.

O tronco da 'árvore do saber' seria a própria Filosofia, que originalmente reuniria em seu seio a totalidade do conhecimento; com o crescimento progressivo da árvore, adubada intensamente pela curiosidade e pela sede de saber própria do ser humano, ela começa a desenvolver os galhos das mais diversas 'especializações' que, embora mantenham suas estreitas ligações com o tronco - nutrem-se de sua seiva e a ele devolvem a energia conseguida pela fotossíntese das folhas em suas extremidades, num processo de mútua alimentação/fecundação - apontam para as mais diversas direções, não guardando entre si outras ligações que não sejam o tronco comum, que não seja a ligação história de sua genealogia. Para ser mais preciso, as ciências relacionam-se todas com seu 'tronco comum' pelo menos no aspecto formal e potencialmente -, embora não consigam, no contexto desse paradigma, relacionar-se entre si. (GALLO, 2008, p.73)

Ao se considerar de fato a possibilidade de uma educação interdisciplinar, é necessário que se busque visualizar o conhecimento e seu processo de construção de outra forma. A metáfora da árvore é utilizada tradicionalmente para compreender o campo dos vários saberes. Esse modelo requer uma hierarquização do saber, pois essa é a forma de mediatizar e regular a cadeia de informações pelas vias internas da árvore do conhecimento. "A frondosa árvore que representa os saberes apresenta-os de forma disciplinar: fragmentados - os galhos - e hierarquizados - os galhos ramificam-se e não se comunicam entre si, a não sei que passem pelo tronco" (GALLO, 1994, p. 29).

Apesar de ser uma metáfora botânica, o paradigma arborescente representa uma concepção mecânica do conhecimento e da realidade, repetindo a fragmentação cartesiana do saber, corolário das concepções científicas modernas.

Os sistemas arborescentes são sistemas hierárquicos que comportam centros de significação e de subjetivação, autômatos centrais, assim como memórias organizadas. Os modelos correspondentes são aqueles em que um elemento não recebe suas informações senão de uma unidade superior, e uma afetação subjetiva, de ligações preestabelecidas. Isso fica claro nos problemas atuais da informática e das máquinas eletrônicas, que conservam ainda o mais velho pensamento, na medida em que confere o poder a uma memória ou a um órgão central. (DELEUZE; GUATTARI, 1995, p.25).

Esse sistema de produção de conhecimento representa uma forma mecânica de apreensão da realidade, e permanece ainda impregnado nas bases da maior parte das 
entidades científicas exercendo domínio sobre os veículos de produção e circulação de saberes. O paradigma mecanicista, que surgiu na modernidade clássica com René Descartes, promoveu o que hoje entende-se por compartimentarização do conhecimento, em que o conteúdo é analisado em sua forma fragmentada, separada e dividida da complexidade da realidade. Isso deu origem à especialização do conhecimento e, consequentemente, ao formato disciplinar da educação que conhecemos.

Segundo Chalmers (1981), Francis Bacon foi um dos primeiros teóricos a articular o que é o método científico moderno. Propôs que a finalidade da ciência seria proporcionar melhores condições de vida ao gênero humano na terra e, para isso, deveria coletar fatos através da observação organizada e derivar, a partir daí, novas teorias. A teoria da indução foi formulada por Bacon com a finalidade de descrever de forma minuciosa as técnicas, cuidados e procedimentos investigativos dos processos naturais. Na percepção de Bacon, saber é poder. Para dominar a natureza é necessário conjugar o seu método indutivo com observações empíricas, experimentos, experiências, ou seja, é preciso conhecer as leis que regem a natureza por meios comprovados. Percebe-se, aí, o caráter essencialmente prático da ciência, fundado numa razão eminentemente instrumental, concretizada no progressivo desenvolvimento tecnológico. A percepção da natureza como palco das intervenções humanas e do conhecimento como fundamento necessário da ação, presente no pensamento baconiano, tornar-se-á, então, com o desenvolvimento tecnocientífico da modernidade, parte essencial da nova visão de mundo. De fato, todo processo de desenvolvimento uente das sociedades atenta para essa lógica que destitui valores intrínsecos da natureza e a subordina ao poder de conhecimento e transformação do pensamento científico moderno.

De acordo com Santos (2001), Descartes em seu método dedutivo, parte das ideias para as coisas e assegura o primado da metafísica como fundamento definitivo da ciência. Para Descartes, segundo Santos (2001, p. 63), "as idéias que presidem a observação e a experimentação são as ideias claras e distintas a partir das quais se pode ascender a um conhecimento mais profundo e rigoroso da natureza". Essas ideias, são as ideias matemáticas. A matemática possibilitou á ciência moderna o instrumento de investigação, a lógica da investigação e o paradigma de representação da própria estrutura material.

O método cartesiano baseia-se em quatro regras básicas, que, de acordo com Descartes, são eficientes para conduzir o espírito à verdade. A primeira regra é a evidência, ou seja, o objeto deve ser exposto com clareza; a segunda regra é a decomposição, é necessário dividir em tantas partes, em quantas forem necessárias; a terceira regra é a ordenação, que torna indispensável partir das questões mais simples para as mais complexas; por fim, a revisão, no qual se faz a recapitulação geral para se ter a certeza de que nada foi omitido (CHALMERS, 1981).

Para Descartes, o primado do sujeito é o fundamento para se atingir o conhecimento. Os desdobramentos do método cartesiano, baseado no princípio das ideias claras e distintas, e a proposição empírica dos fatos e das coisas, ou seja, as ideias e as confirmações empíricas dão consistência ao paradigma da ciência moderna. É possível a partir de então, falar de um modelo global, isto é, ocidental, de racionalidade científica (SANTOS, 2001). 
Mas será, de fato, que o pensamento e o conhecimento acompanham a estrutura proposta pelo paradigma arborescente? Não será esse paradigma um modelo composto a posteriori e sobreposto ao conhecimento já produzido, como forma de incorpora-lo, categoriza-lo, facilitando dessa forma o acesso a ele e seu domínio, levando mesmo a instaurar a estrutura de novos conhecimentos a serem elaborados? Contudo, não seria razoável considerar que o pensamento procede - ou possa proceder - de outra forma, menos hierarquizada e mais caótica?

\section{Transformações Contemporâneas: Pensando como Rizoma}

Em contrapartida ao pensamento arborescente, os teóricos Deleuze; Guattari (1995), ao criticar as formas estabelecidas de compreensão das ciências modernas e manutenção de conhecimentos, engendram um inovador ponto de vista filosófico, tratando com considerável relevância acerca da construção do pensamento e da racionalidade como um todo; propõem então a perspectiva rizomática. Esse conceito é uma resposta à metáfora da árvore que se vai ramificando e que representa a lógica clássica e os procedimentos binários e dicotômicos. Este conceito foi emprestado da Botânica, que define os sistemas de formações aéreas, ligadas à parte subterrânea de plantas flexíveis, que dão brotos e raízes adventícias na sua parte inferior. Descreve-se o rizoma, mediante à imagem de bulbos e tubérculos de múltiplas ramificações. Serve para indicar um modelo semântico oposto às noções de árvore, com hierarquia, centro e ordem de significação (CHALMERS, 1981).

Segundo Deleuze; Guattari (1995), a proposta rizomática, como apresentada no tópico anterior tem inerente em sua concepção á responsabilidade de compreender o mundo em toda a sua complexidade e amplitude; os autores propõem que para tanto, é necessário que se tenha uma interpretação em rede, horizontal, dos saberes formando assim um rizoma, uma raiz em que se entrecruzam e fixam diversas conexões, em vários pontos, os temas e as idéias.

Nesta perspectiva, Deleuze; Guattari (1995, p.58) afirmam: "o que chamamos de rizoma é precisamente um sistema aberto", ou seja, o que é predominante no modelo rizomático é o descentramento que causa em relação ao paradigma predominante de pensamento: o da árvore.

Se o rizoma se opõe a árvore, é essencialmente sobre a impossibilidade de ligações diretas no modelo arbóreo, pois toda ligação, aí, necessita de passar pelo tronco, ou seja, toda associação é determinada por um centro. A existência de centros supõe hierarquias, onde o eixo de suporte, ou uma estrutura sobrecodificadora, decalca o que já está dado. A lógica da árvore é, portanto, a lógica do mesmo, toda lógica da árvore é uma lógica do decalque e da reprodução. [...] A árvore articula e hierarquiza os decalques, os decalques são como folhas da árvore (DELEUZE; GUATTARI, 1995, p.21).

Nesse campo, frequentemente uma unidade superior determina as conexões estabilizando-as previamente e dando seu significado. Enquanto que o rizoma, pode ser interrompido "em um lugar qualquer, e também retoma segundo uma ou outra de suas linhas e segundo outras linhas" (idem, p. 18). Não se justifica então, ao contrário da 
árvore, o assentamento em uma estrutura essencial ou em um modelo gerativo. $\mathrm{O}$ rizoma é "estranho a qualquer idéia de eixo genético ou de estrutura profunda" (idem, p. 21).

O rizoma distingui-se da árvore porque não se hierarquiza, pois não envolve significações prévias e nem pode ser reduzido a uma unidade. O rizoma é continuamente múltiplo, e só opera a partir do agenciamento que faz com outro rizoma que pode ser conectado em múltiplos pontos, de acordo com a sua cartografia. O rizoma é devir, pois "não tem começo nem fim, mas sempre um meio pelo qual ele cresce e transborda" (idem, p. 32).

Deleuze e Guattari (1995) dão algumas pistas sobre a produção de um rizoma e fazem isso elaborando princípios, que visam justamente reafirmar a falta de uma configuração prévia.

Os princípios do rizoma são:

$1^{\circ}$ e $2^{\circ}$ - Princípios de conexão e heterogeneidade: "qualquer ponto do rizoma pode ser conectado a qualquer outro e deve sê-lo" (autor, ano, p. 15). A metáfora da árvore ou raiz remete-se a centros de poder, à hierarquia, estruturas e relações binárias e biunívocas, enquanto o princípio aqui referido envolve cadeias semióticas de toda natureza e conectadas a diversos modos de codificação. "Um rizoma conecta componentes semióticos de organização de poder que remetem às artes, às ciências e às lutas de classes" (autor, ano, p.17). Os acessos de um rizoma são múltiplos, fazendo com que ele não tenha centro e que ele tome qualquer direção e forma. Não existe forma previa, nem determinismos, as conexões são feitas por contágio ou contato.

Num rizoma, ao contrário, cada traço não remete necessariamente a um traço linguístico: cadeias semióticas de toda natureza são aí conectadas a modos de codificação muitos diversos, cadeias biológicas, políticas, econômicas, etc,..., colocando em jogo não somente regime de signos diferentes, mas também estatuto de estado de coisas (DELEUZE; GUATTARI, 1995, p.15).

$3^{\circ}$ - Princípio de multiplicidade: os autores preferem usar a expressão multiplicidade ao invés de múltiplo - cuja ausência de unidade seria sua característica principal. Assim, na esfera da multiplicidade não faz sentido se falar de sujeito ou de objeto, já que se trata aqui de grandezas e determinações que se ampliam de acordo com seus agenciamentos. "Um agenciamento é precisamente este crescimento das dimensões numa multiplicidade que muda necessariamente de natureza à medida que ela aumenta suas conexões" (idem, p.17). As multiplicidades são linhas, que de modo algum possuem pontos fixos. Além disso, só existe uma unidade ou identidade na multiplicidade quando se elabora, ou processos de subjetivação, ou processos de significação - assim sendo, dissimulam-se essências. Assim, se de um lado a unidade cria uma sobrecodificação da multiplicidade, produzindo uma dimensão vazia de sentido; de outro o rizoma produziria um plano de consistência que permanece sempre em expansão e movimento, o que não possibilita que ele seja capturado pela sobrecodificação. 
As multiplicidades se definem pelo fora: pela linha abstrata, linha de fuga $^{2}$ ou desterritorialização segundo a qual elas mudam de natureza ao se conectarem às outras. (...) As multiplicidades planas a $n$ dimensões são a-significantes e a-subjetivas. Elas são designadas por artigos indefinidos, ou antes partitivos (DELEUZE; GUATTARI, 1985, p.18).

$4^{\circ}$ - Princípio de ruptura a-significante: Todo rizoma compreende linhas de segmentaridade, que o caracterizam como estratificado, territorializado e com o significado organizado. Contudo, tais linhas podem ser rompidas e difundidas umas nas outras, reaproximando-se, e até reconstituindo o conjunto original. Considerando esse dualismo, ele também possui uma característica de desterritorialização. Ele não tem um começo ou fim específicos, mas um meio no qual ele cresce e transborda (DELEUZE; GUATTARI, 1995).

$5^{\circ}$ e $6^{\circ}$ - Princípio de cartografia e de decalcomania: O método cartográfico vai funcionar como o instrumento que vai "fotografar" o acontecimento, tal cartografia nos mostra que ele possui entradas múltiplas. $\mathrm{O}$ rizoma pode ser acessado de qualquer ponto, possibilitando daí remeter a quaisquer outros em seu território. O paradigma arborescente remete ao mesmo, pois toda a lógica da árvore é uma lógica da cópia, da reprodução. O rizoma não se baseia em nenhum modelo estrutural ou gerativo, ou seja, não se constitui a partir de uma estrutura profunda centrada em uma unidade objetiva. $\mathrm{O}$ rizoma não é um decalque, que reproduz estruturas. O rizoma se assemelha a um mapa, uma vez que possui caráter aberto, conectável e suscetível de receber modificações. Por isso ele é um sistema a-centrado não hierárquico e não significante, definido apenas por uma circulação de estados (DELEUZE; GUATTARI, 1995).

Se o conhecimento for pensado como rizoma e não como árvore, as disciplinas já não seriam gavetas que não se comunicam, mas tenderiam a soar como linhas que se misturam, teia de possibilidades, de conexões, multiplicidade de nós, de interconexões. A noção de rizoma é contributiva principalmente nas discussões quanto a natureza, abrangência da área e_suas inter-relações com outros domínios. Além disso, o conceito de rizoma traz á tona as reflexões acerca da organização do conhecimento, pondo em choque as estruturas rígidas e planificadas de representação, assim como questiona os aspectos hierárquicos e unilaterais das mesmas.

Para Morin (2003), os saberes tradicionais foram submetidos a um processo reducionista que ocasionou a perda das noções de multiplicidade e diversidade.

O sistema educativo fragmenta a realidade, simplifica o complexo, separa o que é inseparável, ignora a multiplicidade e a diversidade. As disciplinas como estão estruturadas só servem para isolar os objetos do seu meio e isolar partes de um todo. Eliminam a desordem e as contradições existentes, para dar uma falsa sensação de arrumação. A educação deveria romper com isso mostrando as correlações entre os

\footnotetext{
${ }^{2}$ A linha de fuga marca, ao mesmo tempo, a realidade de um número de dimensões finitas que a multiplicidade preenche efetivamente; a impossibilidade de toda dimensão suplementar, sem que a multiplicidade se transforme segundo esta linha; a possibilidade e a necessidade de achatar todas estas multiplicidades sobre o mesmo plano de consistência ou de exterioridade, sejam quais forem suas dimensões. (DELEUZE; GUATTARI, 1995, p. 17).
} 
saberes, a complexidade da vida e dos problemas que hoje existem (MORIN, 2003, p. 22).

A tarefa de romper com a disciplinarização, só será possível, através da filiação a outro paradigma de conhecimento como o rizomático que aqui foi proposto. A filiação a esse modelo significa, também, redesenhar o mapa estratégico do poder no campo da(s) ciência(s) e no campo da educação, conduzindo as relações numa outra dimensão.

\section{Considerações Finais}

A compreensão de se estar vivendo um tempo marcado por mudanças econômicas, culturais, sociais e políticas diferentes daquelas que foram características da modernidade é imprescindível para se pensar o momento contemporâneo. Apesar dessas transformações, pode-se observar que os pressupostos epistemológicos da modernidade ainda permanecem invadindo e atravessando o nosso cotidiano. Como consequência desses processos, o conhecimento ganha uma dimensão que ultrapassa o limitado campo disciplinar, reivindicando novos conceitos e práticas. Assim, torna-se importante pensar essa nova prática de conhecimento como construção interdisciplinar orientado na investigação teórica que produza ações interdisciplinares que envolva diferentes áreas, para responder a complexa variedade de demandas observadas atualmente na educação. Faz-se então necessário abrir o campo de visão das áreas do conhecimento, negando certezas dogmáticas e isolamentos teóricos em função da abertura à pluralidade de relações e perspectivas por meio de um olhar mais crítico e reflexivo sobre o mundo e sobre a própria idéia de conhecimento.

Entretanto, algumas questões parecem estar sempre se repetindo: A primeiro delas é como construir um conhecimento que nos possibilite ultrapassar modelo de fragmentação do saber tradicional, baseado em disciplinas especificas que dialogam muito pouco entre si. A segunda questão que precisa ser pensada é o que fazer com a construção já realizada que passou a supervalorizar a especialidade. E finalmente, de que forma seria possível viabilizar a construção de processos que possam ser utilizados para transpor as lacunas do conhecimento interdisciplinar. Inicialmente, a inquietação gerada por esses questionamentos parece criar uma atmosfera de resistência à mudança.

Parece que é justamente essas inquietações que poderão estimular as potencialidades de mudança do saber linear para o saber interdisciplinar onde o conhecimento é construído por todos de maneira colaborativa e participativa. Essa construção individual e, ao mesmo tempo, coletiva parece possibilitar uma nova percepção do saber do outro, permitindo maior valorização do coletivo em favor do conhecimento. $\mathrm{O}$ entendimento do movimento interdisciplinar necessita ser, mais do que uma aproximação de disciplinas, uma interação em que a troca de saberes assinale a interdependência e a necessidade entre as áreas do conhecimento.

\section{Referências}

BACON, Francis. Novum Organum. São Paulo, Abril Cultural, 2. Ed., 1979.

CHALMERS, Alan. O que é ciência afinal? Brasília: Editora Brasiliense, 1981.

DELEUZE, Gilles; GUATTARI, Felix. Mil Platôs: capitalismo e esquizofrenia. São Paulo:Editora 34, 1995, (v. 1). 
DELUMEAU, Jean. A civilização do Renascimento. Lisboa: Edições 70, 2004.

GALLO, Sílvio. Educação e interdisciplinaridade. In: Impulso, vol. 7, n. 16. Piracicaba: Ed. Unimep, 1994.

Deleuze \& a Educação. Belo Horizonte: Autêntica, 2008.

GUATTARI, Felix.; ROLNIK, Sueli. Notas descartáveis sobre alguns conceitos. In: Micropolítica - cartografias do desejo. Petrópolis: Vozes, 1986.

KRESS, Renato. Metodologia da contemporaneidade. Disponível em <http://www.consciencia.net/2003/07/26/kress.html>.

MORIN, Edgar. Ciência com consciência . Rio de Janeiro: Bertrand Brasil, 2000.

MORIN, Edgar.; LE MOIGNE, Jean-Louis. A inteligência da complexidade. 3ed. São Paulo: Petrópolis, 2000

MORIN, Edgar. A Escola mata a curiosidade.. Entrevistadora: P. Gentili. Nova Escola, São Paulo, edição 168, dez. 2003.

SANTOS, Boaventura de Sousa. Da ciência moderna ao novo senso comum. In:

A crítica da razão indolente. Contra o desperdício da experiência. v. 1, 3. ed.

São Paulo. Cortez, 2001.

STENGERS, Isabelle . A Invenção das ciências modernas. São Paulo: Ed. 34, 2001.

ROUANET, Sergio Paulo. Mal-estar na modernidade. São Paulo: Companhia das Letras, 1993. 